EXTENDED REPORT

\title{
Sodium hyaluronate (hyaluronic acid) promotes migration of human corneal epithelial cells in vitro
}

\author{
J A P Gomes, R Amankwah, A Powell-Richards, H S Dua
}

Br J Ophthalmol 2004;88:821-825. doi: 10.1136/bjo.2003.027573

See end of article for authors' affiliations

.....................

Correspondence to: Professor H S Dua,

Division of Ophthalmology and Visual Sciences, B Floor, Eye Ear Nose Throat Centre, University

Hospital, Queens Medical Centre, Nottingham NG7

$2 \mathrm{UH}, \mathrm{UK}$; harminder.

dua@nottingham.ac.uk

Accepted

22 September 2003

\begin{abstract}
Purpose: Sodium hyaluronate (hyaluronic acid) is known to promote corneal epithelial wound healing in vivo and in vitro, in animal experiments. Sodium hyaluronate is the ligand for CD44, a cell surface adhesion molecule which has been found on normal human corneal epithelial cells. The purpose of this study was to investigate the effect of sodium hyaluronate on human corneal epithelial cell migration, proliferation, and CD44 receptor expression.

Methods: Human corneal epithelial cell cultures were established from 32 donor corneoscleral rims and maintained separately in three different culture conditions: (1) culture medium only, (2) sodium hyaluronate enriched $(0.6 \mathrm{mg} / \mathrm{ml})$ medium, and (3) hydroxypropylmethylcellulose enriched $(2.5 \mathrm{mg} / \mathrm{ml})$ medium. The total area of migrating epithelial cell sheets in each case was measured by planimetry on days $4,8,12$, and 16. Cytospin preparations of cells cultured in the different culture conditions were examined immunohistochemically for proliferation and CD44 receptor expression using antibodies directed against Ki67 and CD44 respectively.

Results: Cells cultured in the presence of sodium hyaluronate showed significantly increased migration at days 12 and 16 (Friedmen test: $p=0.0012$, day 16; $p=<0.001$, day 12) compared with cells cultured in the other media. There was no difference in cell proliferation (Ki67) or CD44 expression on cells cultured in the different culture conditions.

Conclusions: Sodium hyaluronate promotes migration but not proliferation or CD44 expression on human corneal epithelial cells in vitro. The beneficial effect of sodium hyaluronate in corneal wound healing is likely to be related to rapid migration of cells leading to rapid wound closure. This may be facilitated by the adhesion between CD44 on the cells and hyaluronic acid, which coats the surface of the denuded cornea.
\end{abstract}

$\mathrm{T}$ he corneal epithelium forms an integral part of the ocular surface and is necessary for maintaining a clear and proper functioning cornea. When compromised, it is therefore important that it is rapidly regenerated. Epithelial healing at the corneal surface involves the centripetal and circumferential (along the limbus) migration of epithelial cell sheets from the remaining intact epithelium, proliferation of basal epithelial cells surrounding the defect to restore the normal multilayered architecture of the epithelium, and anchoring of the newly regenerated epithelium to underlying connective tissue. ${ }^{1-3}$

Sodium hyaluronate is a naturally occurring glycosaminoglycan of the extracellular matrix that plays an important role in development, wound healing, and inflammation. ${ }^{4}$ Its viscoelastic properties have rendered it ideally suited for use in ophthalmic practice to protect the corneal endothelium and to maintain the anterior chamber depth during intraocular surgery. ${ }^{4-6}$ It has also been used in the treatment of dry eyes because of its long ocular surface residence time..$^{711}$ Recent experiments in animals have shown that sodium hyaluronate promotes corneal epithelial wound healing by stimulating the migration, adhesion, and proliferation of the corneal epithelium. ${ }^{42}{ }^{13}$ The mechanism of action of sodium hyaluronate on these cell functions remains controversial. ${ }^{13-16}$ Human studies have been confined to the in vivo topical instillation of sodium hyaluronate drops in eyes with epithelial problems. ${ }^{17} 18$

Sodium hyaluronate is a ligand for CD44, a transmembrane cell surface adhesion molecule. ${ }^{19}$ The CD44 receptor has been characterised on normal human corneal epithelial cells. It has enhanced expression in inflammation and allograft rejection suggesting its importance in corneal epithelial cell physiology. ${ }^{19}{ }^{20}$ Its expression has also been found to correlate with corneal re-epithelialisation, suggesting its involvement in cell to cell and cell to substratum interactions that mediate cell migration during re-epithelialisation. ${ }^{21}$ Studies have also shown that CD44 expression is associated with proliferation of epithelial cells. ${ }^{22-25}$ The reason for this association is not known.

Due to the possible implications of sodium hyaluronate on wound healing in humans, we investigated its effect on human corneal epithelial cell migration and proliferation and determined whether its presence caused upregulation of the CD44 receptor.

\section{MATERIALS AND METHODS}

Corneal epithelial cell cultures, obtained from human donor explants, were maintained in three different culture conditions: (1) standard growth medium only (SM), (B) standard growth medium enriched with hydroxypropylmethyl cellulose (HPMC) (Ocucoat, $2.5 \mathrm{mg} / \mathrm{ml}$ ) (Storz Ophthalmics, Clearwater, FL, USA), and (3) standard growth medium enriched with sodium hyaluronate ( $\mathrm{SH}$ ) (Healon, $0.6 \mathrm{mg} / \mathrm{ml}$ ) (Pharmacia \& Upjohn, Uppsala, Sweden). The viscosities of hydroxypropylmethyl cellulose and sodium hyaluronate enriched media were equal at the concentrations used. Corneal epithelial cell migration, cell proliferation, and number of cells expressing CD44 were compared in the three groups.

\section{Corneal epithelial cell culture}

Primary cultures of human corneal epithelial cells were established from $2 \mathrm{~mm}$ limbal explants obtained from 32 donor corneoscleral rims following corneal transplantation, using the method described before by Dua et al. ${ }^{26}$ Donor age

Abbreviations: HPMC, hydroxypropylmethyl cellulose; $\mathrm{SH}$, sodium hyaluronate; SM, standard growth medium; TBS, TRIS buffered saline. 
ranged from 30 to 74 years. Briefly, under aseptic conditions and using the dissecting microscope, each donor corneoscleral rim was divided into six equal pieces. The endothelial and posterior stromal layer was carefully peeled off and each explant was placed separately, with the epithelial surface facing upwards, in the centre of a $35 \mathrm{~mm}$ Falcon Primaria tissue culture dish (Becton Dickinson, Oxford, UK). These were left covered in a laminar flow cabinet at room temperature for 5 minutes and then covered in growth medium (Dulbecco's MEM/Nut Mix F-12) (DMEM) (Gibco BRL, Life Technologies, Paisley, UK) supplemented with fetal bovine serum (5\%) (Gibco); dimethyl sulfoxide (DMSO) $(0.5 \% \mathrm{v} / \mathrm{v})$ (Sigma-Aldrich, Dorset, UK); gentamicin $(5 \mu \mathrm{g} /$ $\mathrm{ml}$ ) (Roussel Laboratories Ltd, Uxbridge, UK); epidermal growth factor $(10 \mathrm{ng} / \mathrm{ml})$ (Gibco); bovine insulin $(5 \mu \mathrm{g} / \mathrm{ml})$ (Gibco) and cholera toxin $(0.1 \mu \mathrm{g} / \mathrm{ml})$ (Gibco). Cultures were incubated at $37^{\circ} \mathrm{C}$, in $5 \%$ carbon dioxide in humid air. The epithelial cell morphology of the cultures was evaluated daily by phase contrast microscopy. At day four, cell migration from the explants was measured and three similar cultures were selected and randomly assigned to one of the three culture conditions: standard medium (SM) alone, medium with hydroxypropylmethyl cellulose (HPMC) (Ocucoat, $2.5 \mathrm{mg} / \mathrm{ml}$ ) (Storz Ophthalmics), and medium with sodium hyaluronate $(\mathrm{SH})$ (Healon, $0.6 \mathrm{mg} / \mathrm{ml}$ ) (Pharmacia \& Upjohn). Thus explants from the same donor rim were maintained in the three different conditions and compared. Explants were left in the culture dish for the duration of the incubation. Culture medium was changed every fourth day. Epithelial cell migration from the explants was measured on days 8,12 , and 16 . The advancing edge of the migrating epithelial cell sheet was outlined on the culture dish and the total area of the sheet was determined by planimetry and expressed in square millimeters.

\section{Intragroup variation of cell migration}

Three similar cultures, with respect to area of cell migration at day four, from the same donor rim were maintained in each of the three culture conditions, for 16 days. Thus of nine cultures selected, three were maintained in SM, three with HPMC, and three with SH. Measurements of area of cell migration were taken on days 8,12 , and 16 .

\section{Cytospins}

On the 16th day of culture, cytocentrifuge preparations of epithelial cells were performed. Adherent cells were first detached from the culture dish by incubation with Trypsin/ EDTA $(0.05 \%)$ (Gibco) at $37{ }^{\circ} \mathrm{C}$ for 15 minutes. Detached cells were washed twice in DMEM. The Trypan blue dye exclusion test was carried out to ascertain whether any of the culture conditions had an adverse effect on cell membrane integrity. The number of cells in suspension was adjusted to a concentration of $5 \times 10^{4}$ cells $/ \mathrm{ml}$. Cytospin preparations of 5000 cells/slide were made by centrifugation in a cytospin for 10 minutes at $1000 \mathrm{rpm}, 100 \mathrm{ul} / \mathrm{cup}$. Slides were air dried, fixed in acetone for 10 minutes and stained.

\section{Immunohistochemistry}

Ki67 (cell proliferation marker)

Cell proliferation in the different culture conditions was determined by the use of monoclonal antibody, which reacts with a nuclear antigen Ki67, of proliferating human cells in Gl-M but not G0 phase. Primary rabbit anti human Ki67 antibody (Dako, Carpentiria, CA, USA) was applied to the cytospin preparations at a 1:40 dilution for 1 hour at room temperature in a moist chamber. Excess antibody was removed by washing slides in TRIS buffered saline (TBS) (Sigma). Negative controls with TBS and an irrelevant antibody, were set up alongside test slides. Flourescein
(FITC) conjugated swine antirabbit antibody (Dako) 1:20 dilution for 30 minutes, was used as secondary antibody. Slides were mounted in glycerol/phosphate buffered saline. The proportion of positively labelled cells in each cytospin was determined by analysing 200 cells per slide using a fluorescent microscope.

\section{CD44 (cell adhesion molecule)}

Expression of CD44 by cells cultured in the different culture conditions was determined using an antibody directed against the CD44 receptor. Cytospin preparations were stained using the standard alkaline phosphatase anti-alkaline phosphatase (APAAP) method..$^{27}$ Following incubation with the primary antibody, mouse antihuman CD44 antibody (Dako), 1:40 dilution for 1 hour at room temperature in a moist chamber, slides were stained with rabbit antimouse immunoglobulin (Dako) and then APAAP complex (Dako) at 1:50 and 1:100 dilutions respectively for 30 minutes. Negative controls with TBS and an irrelevant antibody, were also set up. All antibodies were diluted in TBS and between each staining, slides were washed three times in TBS. The reaction product was developed with Fast Red TR salt (Sigma) as chromogen for the APAAP. Slides were counterstained with haematoxylin (Meyer's). The proportion of positive red stained cells in each cytospin preparation was determined microscopically by analysing cells in five random high power fields.

\section{Statistical analysis}

The comparison among migration of groups SH, HPMC, and SM was performed separately for each day, through repeated measures of ANOVA. Repeated measures of ANOVA was also used to study intragroup variation for epithelial migration separately for SH, HPMC, and SM. The comparisons for proliferation with Ki-67 and CD44 expression among groups SH, HPMC, and SM were performed using Friedmans and Wilcoxon test. The significance level adopted in this study was $5 \%(\alpha=0.05)$ and the SPSS system (SPSS Inc, Chicago, IL, USA) was used for the statistical analysis.

\section{RESULTS \\ Migration}

Corneal epithelial cells began to migrate from the limbal explants between the second and third day of culture. The cells tended to have a polygonal or cobblestone like morphology migrating as continuous sheets around the explant and towards the edge of the culture dish. A difference in the rate of cell migration with time was detected among the different corneoscleral rims used. However, no significant intra rim difference was noted amongst the triplicates in the same culture conditions ( $\mathrm{SH}: \mathrm{p}=0.300$, HPMC: $\mathrm{p}=0.277$, and SM: $p=0.676$ ). The different culture conditions did not affect cell morphology. Migration rates were however affected by the different culture conditions. On days 4 and 8 there was no significant difference in migration of cells cultured in the different conditions. On day 12, cells cultured in $\mathrm{SH}$ presented a significantly higher migration value than cells cultured in HPMC $(p=0.007)$ and SM $(p=0.025)$. However there was no difference between cells cultured in HPMC and SM $(p=0.630)$. On day 16 , the three groups were significantly different among themselves ( $\mathrm{SH} v \mathrm{SM}$ : $\mathrm{p}=0.001 ;$ SH $v$ HPMC: $\mathrm{p}=0.003$, and HPMC $v$ SM: $\mathrm{p}=0.010)$ (fig 1$)$.

\section{Trypan blue dye exclusion test}

The number of cells that excluded tyrpan blue dye was consistent in the different culture conditions. The number of cells ranged from 97.14 to $99.3 \%$ (mean $98.49 \%$ ) for cells cultured in the SM and 97 to $99 \%$ (mean $98.40 \%$ ) and 97 to 


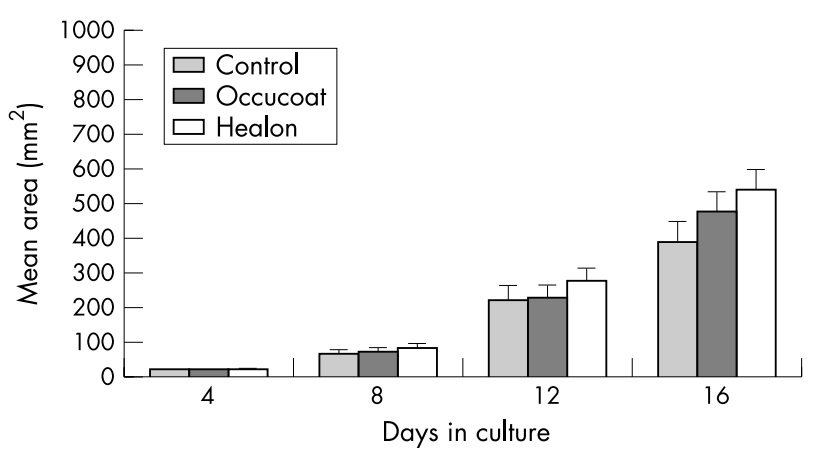

Figure 1 Mean area of migrating human corneal epithelial cell sheets in the different culture conditions-standard medium (control), hydroxypropyl methyl cellulose (Occucoat), and sodium hyaluronate (Healon) - over time. Error bars = standard error of mean.

99.58\% (mean 98.14\%) for cells cultured in HPMC and SH enriched media respectively.

\section{Ki67 (cell proliferation)}

Ki67 expression, an indication of the number of proliferating cells, was not significantly different in the three conditions $(p=0.957)$. The mean percentage of proliferating cells cultured in SM was 8.16, and 8.66 and 8.40 for HPMC and $\mathrm{SH}$ media respectively (fig $2 \mathrm{~A}$ and $\mathrm{B}$ ). There was no statistical difference in the total number of cells obtained from the three different culture conditions ( SM $v$ HPMC $\mathrm{p}=0.267$, SM $v \mathrm{SH} \mathrm{p}=0.149$, HPMC $v$ SH $\mathrm{p}=0.197)$.

\section{CD44}

CD44 expression by the cells in the three culture conditions was also not significantly different, with a mean percentage of 98.56 for SM and 98.58 and 98.4 respectively for HPMC and SH enriched media $(\mathrm{p}=0.819)$ (fig $3 \mathrm{~A}$ and $\mathrm{B}$ ).

\section{DISCUSSION}

The normal corneal basement membrane is composed of collagen type I and IV and laminin. ${ }^{28-30}$ There is virtually no $\mathrm{SH}$ or fibronection, which are only present after an epithelial lesion initiates the healing process. ${ }^{14}$ These two substances seem to serve as a temporary matrix for the migration of epithelial cells during wound healing. ${ }^{14}$ The coordinated appearance and disappearance of fibronection receptors (integrins) and fibronectin onto corneal epithelial cell surface have been shown during migration. ${ }^{1431} 32 \mathrm{SH}$ levels also increase during epidermal and corneal epithelial healing induced in rabbits. ${ }^{33-35}$ On the other hand, keratan sulfate and condroitin sulfate which constitute, respectively, $65 \%$ and $30 \%$ of the total corneal glycosaminoglicans, decrease during corneal epithelial healing. ${ }^{14} 343637$ Stiebel-Kalish et al ${ }^{38}$ compared histological sections of experimental wound healing animal models and found better morphological regularity and intercellular adhesion in epithelial cells that were treated with SH compared to their control group.

Miyauchi $e t \mathrm{al}^{39}$ reported a stimulatory effect of HA on the migration of rabbit corneal epithelial cells in vitro. The authors also noted that there was a concomitant decrease in the fibronectin concentration and that the effect was inhibited after the addition of hyaluronidase. Nishida et $a l^{40}$ and Nishida et $a l^{13}$ confirmed these observations and showed that fibronectin and $\mathrm{SH}$ both increased rabbit corneal epithelial migration in vitro and that the effect of the two substances was additive. The same stimulatory effect of SH or fibronectin was found in rabbit corneal epithelial cell wound healing in vivo. ${ }^{41-43}$ Nakamura et al $^{14}$ demonstrated that HA binds to the fibrin and heparin binding domain at the $\mathrm{N}$

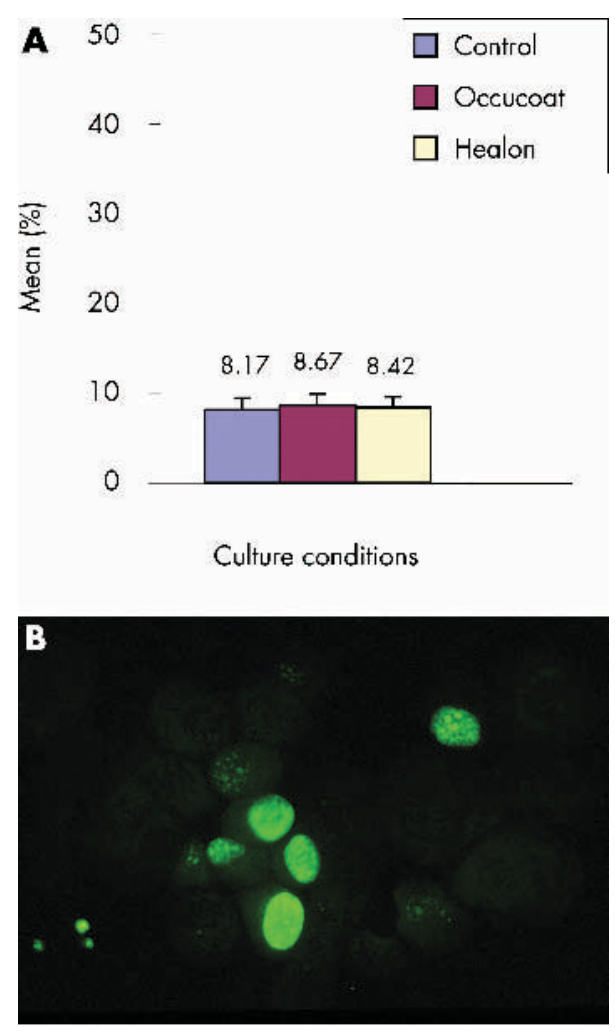

Figure 2 (A) Mean percentage of proliferating (Ki67 positive) human corneal epithelial cells in the different culture conditions - standard medium (control), hydroxypropyl methyl cellulose (Occucoat), and sodium hyaluronate (Healon)-studied on day 16 of culture. Error bars = standard error of mean. (B) Immunofluorescent staining of a cytospin preparation of cells harvested at day 16 of culture in sodium hyaluronate medium, showing Ki67 positive cells. $(\times 400)$. The staining was identical to that seen with standard medium and hydroxypropyl methyl cellulose (Occucoat) medium.

terminal of fibronectin and facilitates the adhesion of rabbit corneal epithelial cells to the extracellular matrix containing fibronectin. In another study, Nakamura et $a^{42}$ demonstrated that pretreatment with topical fibronectin increased the healing effect of $\mathrm{SH}$ in rabbits corneas in vivo.

Nakamura and Nishida $^{44}$ investigated the interaction between $\mathrm{SH}$ and different extracellular matrix proteins (fibronectin, laminin, and type IV collagen) on corneal epithelial migration using a rabbit corneal culture system. They observed that SH, fibronectin, or collagen type IV, but not laminin, increased migration. Only pretreatment with fibronectin had a synergistic effect with $\mathrm{SH}$ on stimulating epithelial migration. On the other hand, the same authors observed that this effect was only partially inhibited by the addition of antifibronectin serum. Therefore, one can postulate that two possible mechanisms are involved in the potentiation of cell migration by $\mathrm{SH}$-one fibronectin dependent and one fibronectin independent.

The experimental data with regard to the effect of $\mathrm{SH}$ on corneal epithelial wound healing can be summarised thus: (1) all of them used animal models-mostly rabbits-and (2) all of them showed a positive effect on corneal epithelial wound healing. ${ }^{13} 143339424345$ However, clinical data in humans showed controversial results. Yokoi et al ${ }^{18}$ reported a therapeutic effect of $0.1 \%$ HA in 10 eyes that presented with diffuse epithelial keratitis after penetrating keratoplasty. Clinically in patients SH, either by itself or with fibronectin, has been shown to improve epithelial healing. ${ }^{46}{ }^{47}$ Baltatzis et al (Invest Opthalmol Vis Sci 2000;40:S912. ARVO abstracts) 

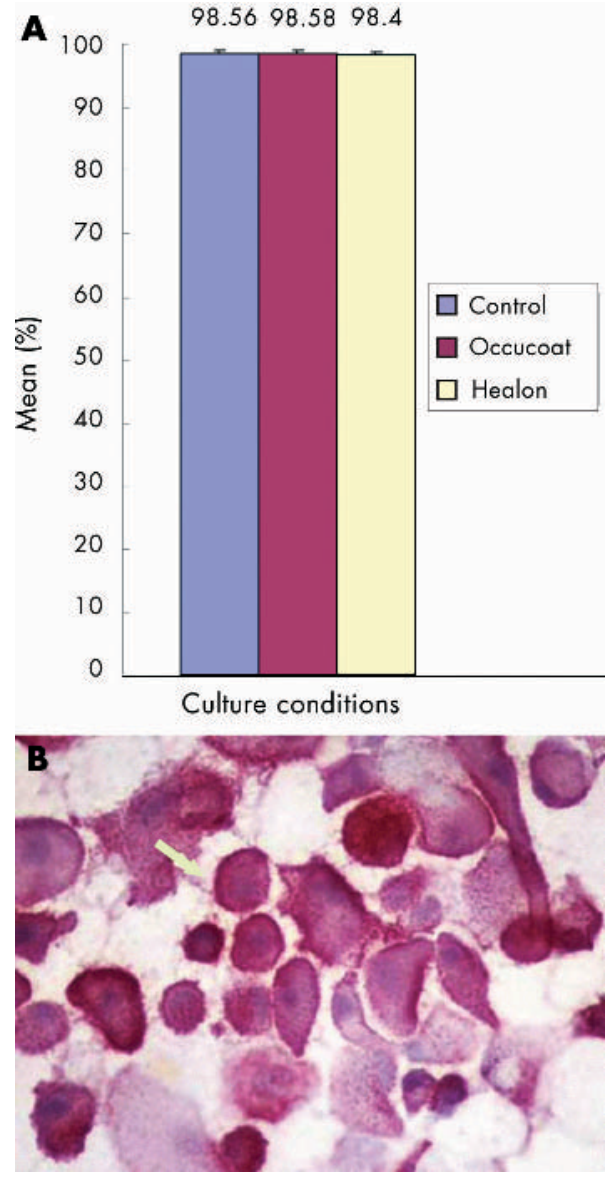

Figure 3 (A) Mean percentage of CD44 positive human corneal epithelial cells in the different culture conditions - standard medium (control), hydroxypropyl methyl cellulose (Occucoat), and sodium hyaluronate (Healon)-studied on day 16 of culture. Error bars = standard error of mean. (B) Immunostaining (alkaline phosphatase anti alkaline phophatase) of a cytospin preparation of cells harvested at day 16 of culture in sodium hyaluronate medium, showing CD44 positive cells. $(\times 400)$. Staining was identical to that seen with standard medium and hydroxypropyl methyl cellulose (Occucoat) medium.

have also reported a positive effect of $\mathrm{SH}$ on corneal epithelial healing after different ocular surgical procedures. On the other hand, in one prospective study comparing $\mathrm{SH}$ with placebo in patients undergoing photorefractive surgery, no difference was noted. ${ }^{48}$

Experimental data obtained from the rabbit model of corneal epithelial wound healing has some limitations: (1) rabbit corneal epithelial cells have different proliferation rates, (2) rabbit corneal epithelial cells undergo a different differentiation process, based on the analysis of specific cytokeratin expression, ${ }^{49}$ (3) rabbit corneal epithelial cells have a more cohesive adherence to fibronectin (in contrast with human corneal epithelial cells) that adheres better to laminin, and (4) rabbit cornea has a different structure from human cornea in that it is thinner and does not possess a Bowman's layer. ${ }^{50}{ }^{51}$ The results obtained from rabbit studies with regard to the effect of SH cannot therefore be directly applicable to human corneal epithelial wound healing. We used the commercially available $\mathrm{SH}$ in the dilution of $0.6 \mathrm{mg} / \mathrm{ml}$. This concentration was based on the results of different experiments that tested different $\mathrm{SH}$ concentrations to stimulate corneal epithelialisation and found better results with concentrations between $0.4-1.0 \mathrm{mg} / \mathrm{ml}^{4}{ }^{44}{ }^{39} 45$ Miyauchi et $a^{39}$ demonstrated that concentrated SH is 100 times more viscous than culture medium and that it inhibits epithelial migration compared with lower SH concentrations. A more viscous medium can probably interfere with the diffusion of nutrients and cell metabolism. In this study therefore the SH concentration of $0.6 \mathrm{mg} / \mathrm{ml}$ was selected to enhance epithelial migration, and the concentration of HPMC selected was such that it yielded the same viscosity to the culture medium. ${ }^{52}$ The significantly increased migration observed with SH medium compared with HPMC medium and standard medium, suggests that the effect was not related to viscosity alone.

Our model of cell migration differed from the animal experiments referred to above. ${ }^{13} 394455$ In the animal models the experiments were carried out on a block of corneal tissue and migration over small distances was measured histologically ${ }^{40}$ In our model, the study groups were established from human corneal explants derived from the same donor and therefore could be matched. Moreover, we determined the intragroup variation to check the reproducibility of our experimental model. Migration was determined through the measurement of the total area covered by the epithelial sheet by planimetry on days $4,8,12$, and 16 . The time was much longer than the animal studies, which extended over a few hours only. ${ }^{4} 13 \quad 1433$ 38-40 42-45

In a clinical study in humans, it was shown that topical use of sodium hyaluronate, applied to the corneal surface during excimer laser surgery promoted rapid wound healing and reduced the occurrence of post ablation haze.. ${ }^{53}$ The study provides a rationale for the clinical use of sodium hyaluronate in patients with corneal epithelial defects, where it may promote wound healing.

Another important component of epithelial healing is cell proliferation. Inoue and Katakami ${ }^{4}$ showed that $\left[{ }^{3} \mathrm{H}\right]$ thymidine incorporation was significantly higher in rabbit epithelial cells that were cultivated with 400 and $1000 \mu \mathrm{g} / \mathrm{ml}$ of $\mathrm{SH}$ compared with epithelial cells from the control group or those that were cultivated with fibronectin. In our study on human epithelial cells, we evaluated epithelial cell proliferation by immunofluorescence using the anti-Ki67 antibody. We found that approximately 8-9\% of the epithelial cells in each group were positive for Ki67, but we did not find a significant difference among the three groups. The similarity in total number of cells and of Ki67 staining cells in the three culture conditions supports the view that SH specifically influences migration, but not proliferation, of corneal epithelial cells.

CD44 is a transmembrane receptor linked to the actin cytoskeleton. It binds to hyaluronate and is also capable of binding fibronectin, laminin, and collagen $\mathrm{I}^{19}{ }^{54}$ There are only a few studies related to the presence of CD44 in the cornea and the results are controversial. Alho and Underhill did not find CD44 in corneal epithelium..$^{55}$ On the other hand, Asari $e t a l^{33}$ demonstrated the presence of CD44 in epithelial and endothelial cells, and in keratocytes of rabbit corneas, and Zhu et $a l^{19}$ demonstrated it in human corneas. These authors observed that CD44 distribution varied depending on the epithelial layer and topographic location on the cornea. In normal corneas, CD44 was mostly found at the membrane of basal epithelial cells. The wing cells expressed maximal CD44 in the more peripheral locations. At the limbus, all epithelial layers were CD44 positive. In corneas that had allogenic corneal graft rejection, trauma, or keratitis, CD44 was observed through all layers of the corneal epithelium. Similarly, epithelial cells from other organs and tissues (such as skin, intestine, lungs and kidney) present the same CD44 expression patterns. Kaya et $a l^{54}$ developed a transgenic mice lineage that did not express CD44 in skin keratocytes and corneal epithelium. These animals presented an abnormal hyaluronate accumulation in the superficial dermis and 
beneath the corneal epithelium. These alterations resulted in changes in dermal elasticity and in cicatricial and inflammatory responses, illustrating the important role of CD44 in SH homeostasis.

In a model of corneal wound healing in rabbits, it has been shown that CD44 expression decreases before epithelial and stromal SH levels, suggesting that CD44 controls $\mathrm{SH}$ concentration in the cornea. ${ }^{33}$ In the present study, we found a high percentage of positive CD44 epithelial cells in all three groups. One can postulate that there is no negative or positive feedback between presence of SH and CD44 expression. As our cultures were derived from limbal explants, our findings conform to the observation made by Zhu et al ${ }^{19}$ who found increased CD44 expression in peripheral corneal epithelial cells.

The beneficial effect of HA on corneal epithelial cell migration may support a role for HA instillation in ocular surface epithelial healing disorders. However, the concentration of HA applied may be critical in eliciting such an effect.

\section{Authors' affiliations}

J A P Gomes, Department of Ophthalmology, Paulista Medical School, Federal University of Sao Paulo, Sao Paulo, Brazil

R Amankwah, H S Dua, A Powell-Richards, Larry A Donoso Laboratory for Eye Research, Division of Ophthalmology and Visual Sciences, University of Nottingham, Nottingham, UK

\section{REFERENCES}

1 Dua HS, Gomes JAP, Singh A. Corneal epithelial wound healing. Br J Ophthalmol 1994;78:401-8.

2 Dua HS, Forrester JV. The corneoscleral limbus in human corneal epithelial wound healing. Am $j$ Ophthalmol 1990;1 10:646-56.

3 Dua HS, Forrester JV. Clinical patterns of corneal epithelial wound healing. Am J Ophthalmol 1987;104:481-9.

4 Inove M, Katakami C. The effect of hyaluronic acid on corneal epithelial cell proliferation. Invest Ophthalmol Vis Sci 1993;34:13-15.

5 Koch DD, Liu JF, Glasser DB, et al. A comparison of corneal endothelial changes after use of healon or viscoat during phacoemulsification. Am J Ophthalmol 1993;115:188-201.

6 Volker-Dieben HJ, Regensburg H, Kruit PJ. A double blind, randomised study of healon GV compared with healon in penetrating keratoplasty. Cornea 1994;13:414-17.

7 Grave EL, Polack FM, Balazs EA. The protective effect of Na Hyaluronate to corneal endothelium. Exp Eye Res 1980;31:119-27.

8 Shimmura S, Ono M, Shinozaki K, et al. Sodium hyaluronate eyedrops in the treatment of dry eyes. Br J Ophthalmol 1995;79:1007-11

9 Snibson GR, Greaves JL, Soper NDW, et al. Precorneal residence times of sodium hyaluronate solutions studied by quantitative gamma scintigraphy. Eye 1990;4:594-602.

10 Aragona P, Papa V, Micali A, et al. Long term treatment with sodium hyaluronate-containing artificial tears reduces ocular surface damage in patients with dry eye. Br J Ophthalmol 2002;86:181-4.

11 DeLuise VP, Peterson WS. The use of topical Healon tears in the management of refractory dry eye syndrome. Ann Ophthalmol 1984;16:823-4.

12 Stuart JC, Linn JG. Dilute sodium hyaluronate (Healon) in the treatment of ocular surface disorders. Ann Ophthalmol 1985;17:190-2.

13 Nishida T, Nakamura M, Mishima H, et al. Hyaluronan stimulates corneal epithelial cell migration. Exp Eye Res 1991;53:753-8.

14 Nakamura M, Mishima H, Nishida T, et al. Binding of hyaluronan to plasma fibronectin increases the attachment of corneal epithelial cells to a fibronectin matrix. J Cell Physiol 1994;159:412-22.

15 Lindquist TD, Edenfield M. Cytotoxicity of viscoelastics on cultured corneal epithelial cells measured by plasminogen activator release. Ref Corneal Surg 1994;10:95-101.

16 Fitzsimmons TD, Fagerholm P, Harfstrand A, et al. Hyaluronic acid in the rabbit cornea after excimer laser superficial keratectomy. Invest Ophthalmo Vis Sci 1992; 33:3011-16.

17 Norn MS. Perioperative protection of cornea and conjunctiva. Acto Ophthalmol 1981;59:587-94.

18 Yokoi N, Yamada J, Nishida K, et al. Effect of sodium hyaluronate on diffuse epithelial keratitis after penetrating keratoplasty. Transplant Proc 1995;27:1412-13.

19 Zhu SN, Nolle B, Dunker G. Expression of adhesion molecule CD44 on human corneas. Br J Ophthalmol 1997;81:80-4.

20 Aruffo A, Stanenkonic I, Melnick M, et al. CD44 is a principal surface recepto for hyaluronate. Cell 1990;61:1303-13.

21 Yu FX, Guo J, Zhang Q. Expression and distribution of adhesion molecule CD44 in healing corneal epithelia. Invest Ophthalmol Vis Sci 1998;5:710-17.

22 Abbasi AM, Chester KA, Talbot IC, et al. CD44 is associated with proliferation in normal and neoplastic human colorectal epithelial cells. Eur J Cancer 1993;29:1995-2002.
23 Lesley J, Hyman R, Kincade PW. CD44 and its interaction with extracellular matrix. Adv Immunol 1993;54:271-335.

24 Gunthert U. CD44: a multitude of isoforms with diverse functions. Curr Top Microbiol Immunol 1993;184:47-63.

25 Mackay CR, Terpe HJ, Stauder R, et al. Expression and modulation of CD44 variant isoforms in humans. J Cell Biol 1994;124:71-82.

26 Dua HS, Singh A, Gomes JAP, et al. Vortex or whorl formation of cultured human corneal epithelial cells induced by magnetic fields. Eye 1996; 10:447-50.

27 Cordell JL, Falini B, Erber WN, et al. Immunoenzymatic labelling of monoclonal antibodies using immune cell complexes of alkaline phosphatase and monoclonal anti-alkaline phosphatase (APAAP complexes). J Histochem Cytochem 1984;32:219-29.

28 Grant DS, Leblond CP. Immunogold quantification of laminine type IV collagen and heparan sulfate proteoglycan in a variety of basement membrane. J Histochem Cytochem 1988;36:271-83.

29 Romanet JP, Mouillon M. Le renouvellement de l'epithelium cornéen. In Rigal D, ed. L'épithélium cornéen. Paris: Société Française d'Ophtalmologie et Masson, 1993:70-88.

30 Dua HS. Stem cells of the ocular surface: scientific principles and clinical applications. Br J Ophthalmol 1995:79:968-9.

31 Murakami J, Nishida T, Otori T. Coordinated appearance of beta- 1 integrins and fibronectin during corneal wound healing. J Lab Clin Med 1992;120:86-93.

32 Grushkin-Lerner LS, Trinkaus-Randall V. Localization of integrin and syndecan in vivo in a corneal epithelial abrasion and keratectomy. Curr Eye Res $1991 ; 10: 75-85$

33 Asari A, Morita M, Sekiguchi T, et al. Hyaluronan, $\mathrm{cd} 44$ and fibronectin in rabbit corneal epithelial wound healing. Jpn J Ophthalmol 1996;40:18-25.

34 Kitano S, Goldman JN. Cytologic and histochemical changes in corneal wound repair. Arch Ophthalmol 1966;76:345-54.

35 Weigel PH, Fuller GM, Leboeuf RD. A model for the role of hyaluronic acid and fibrin in the early events during the inflammatory response and wound healing. J Theor Biol 1986;119:219-34.

36 Hassel JR, Cintron C, Kublin C, et al. Proteoglycan changes during restoration of transparency in corneal scars. Arch Biochem Biophys 1983;222:362-9.

37 Friend J. Physiology of the cornea. In: Smolin G, Thoft RA, eds. The cornea. Scientific foundations and clinical practice. Boston, MA: Little Brown, 1987:16-38.

38 Stiebel-Kalish H, Gaton DD, Weinberger D, et al. A comparison of the effect of hyaluronic acid versus gentamicin on corneal epithelial healing. Eye 1998; 12:829-33.

39 Miyauchi S, Sugiyama T, Machida A, et al. The effect of sodium hyaluronate on the migration of rabbit corneal epithelium. I. An in vitro study. J Ocul Pharmacol 1990;6:91-9.

40 Nishida T, Nakagawa S, Awata T. Fibronectin eye drops for traumatic corneal recurrent erosion. Lancet 1983;2:521-2.

41 Nishida T, Nakagawa S, Nishibayashi C, et al. Fibronection enhancement of corneal epithelial wound healing in rabbit in vivo. Arch Ophthalmol 1984; 102:455-6.

42 Nakamura $M$, Nishida T, Hikida $M$, et al. Combined effects of hyaluronan and fibronectin on corneal epithelial wound closure of rabbit in vivo. Curr Eye Res 1994;13:385-8.

43 Sugiyama T, Miyauchi S, Machida A, et al. The effect of sodium hyaluronate on the migration of rabbit corneal epithelium. II. The effect of topical administration. J Ocul Pharmacol 1991;7:53-64.

44 Nakamura M, Nishida T. Synergistic effects of hyaluronan and fibronectin on epithelial migration in rabbit cornea in vitro. Cornea 1999;18:686-92.

45 Nakamura M, Hikida M, Nakano T. Concentration and molecular weight dependency of rabbit corneal epithelial wound healing on hyaluronan. Curr Eye Res 1992;10:981-6.

46 Reed DB, Mannis MJ, Hills JF, et al. Corneal epithelial healing after penetrating keratoplasty using topical healon versus balanced salt solution. Ophthalmic Surg 1987; 18:525-8.

47 Oe M, Wang H-F, Miyamoto Y. Three cases of persistent corneal epithelial defect successfully treated with the combined use of fibronectin and hyaluronic acid eye drops. Jpn Rev Clin Ophthalmol 1997;91:877-81.

48 Algawi K, Agrell B, Goggin M, et al. Randomized clinical trial of topical sodium hyaluronate after excimer laser photorefractive keratectomy. J Refract Surg 1995;11:42-4.

49 Kiritoshi A, Sundarraj N, Thoft RA. Differentiation in cultured limbal epithelium as defined by keratin expression. Invest Ophthalmol Vis Sci 1991;32:3073-7.

50 Campos M, Raman S, Lee M, et al. Keratocyte loss after different methods of de-epithelialization. Ophthalmology 1994;101:890-4.

51 Campos M, Szerenyi K, Lee M, et al. Keratocyte loss after corneal deepithelialization in primates and rabbits. Arch Ophthalmol $1994 ; 112: 254-60$

52 Buratto L, Giardinni P, Bellucci R, eds. Viscoelastics in ophthalmic surgery. Slack: Thorofare, 1999:1-48.

53 Alio JL, Belda Jl, Shalaby A. Correction of irregular astigmatism with Excimer Laser Assisted by Sodium HYaluronate (ELASHY). Ophthalmology 2001; 108:1246-60

54 Kaya G, Rodriguez I, Jorcano JL, et al. Selective suppression of CD44 in keratinocytes of mice bearing an antisense CD44 transgene driven by a tissuespecific promoter disrupts hyaluronate metabolism in the skin and impairs keratinocyte proliferation. Genes Dev 1997;11:996-1007.

55 Alho AM, Underhill CB. The hyaluronate receptor is preferentially expressed on proliferating epithelial cells. J Cell Biol 1989;108:1557-65 